University of Windsor

Scholarship at UWindsor

\title{
Perceived organizational membership and the retention of older workers
}

Francine K. Schlosser

Odette School of Business, University of Windsor

Marjorie Armstrong-Stassen

Follow this and additional works at: https://scholar.uwindsor.ca/odettepub

Part of the Business Commons

\section{Recommended Citation}

Schlosser, Francine K. and Armstrong-Stassen, Marjorie. (2011). Perceived organizational membership and the retention of older workers. Journal of Organizational Behavior, 32 (2), 319-344.

https://scholar.uwindsor.ca/odettepub/110

This Article is brought to you for free and open access by the Odette School of Business at Scholarship at UWindsor. It has been accepted for inclusion in Odette School of Business Publications by an authorized administrator of Scholarship at UWindsor. For more information, please contact scholarship@uwindsor.ca. 


\title{
Perceived organizational membership and the retention of older workers ${ }^{\dagger}$
}

\author{
MARJORIE ARMSTRONG-STASSEN* AND FRANCINE SCHLOSSER \\ Odette School of Business, University of Windsor, Ontario, Canada
}

Summary Drawing on the perceived organizational membership theoretical framework and the groupvalue justice model, we developed and tested a model predicting older workers' intention to remain with their organization. We hypothesized that human resource practices targeted to older workers would be related to perceived insider status through how older workers perceived their supervisor managed these practices (perceived procedural and interpersonal justice). We also hypothesized that perceived insider status would mediate the relationship between perceived contribution and intention to remain. We conducted two studies to test the hypothesized model. Study 1 participants $(N=236)$ were a diverse group of older workers and Study 2 participants $(N=420)$ were older registered nurses. Using structural equation modeling, we found support for the hypothesized model. All of the hypothesized relationships were significant in Study 2 and all except one were significant in Study 1. Older workers will want to remain a member of their organization when their organization engages in practices tailored to the needs of older workers, their supervisor implements these practices fairly, and their organization conveys that it values the contribution of its older workers thereby fostering a strong sense of belonging. Copyright (C) 2011 John Wiley \& Sons, Ltd.

\section{Introduction}

The aging of labor forces in developed countries around the world means that older workers will play a more prominent role in the workforce in the not-too-distant future (Allen \& Hart, 1998; Beehr \& Bowling, 2002; Mitchell, 2006). According to the United Nations (2007), almost one-third of the working-age population in developed countries will be aged 50 or over by 2050 . As a consequence of workforce aging, employers will need to retain and nurture their older workers (European Foundation for the Improvement of Living and Working Conditions, 2004; Goldberg, 2000). Despite the projections of labor shortages and the need to retain older workers, few employers are actively seeking to retain their older employees (Parkinson, 2002; Peterson \& Spiker, 2005; Rappaport, Bancroft, \& Okum, 2003; Remery, Henkens, Schippers, \& Ekamper, 2003; Rix, 2004; Taylor \& Walker, 1998a, b). In a recent survey of over 28000 employers in 25 countries, only 21 per cent of employers reported that

\footnotetext{
* Correspondence to: Marjorie Armstrong-Stassen, Odette School of Business, University of Windsor, 401 Sunset Avenue, Windsor, Ontario N9B 3P4, Canada. E-mail: mas@uwindsor.ca

${ }^{\dagger}$ Parts of this material are based on data and information provided by the College of Nurses of Ontario. However, the analyses, conclusions, opinions, and statements expressed, herein, are those of the authors, and not necessarily those of the CNO.
} 
they had strategies in place to retain their older workers (Manpower, 2007). Manpower concluded that one of the key reasons that employers are not doing more to retain older workers is simply that they do not yet understand how to do so effectively. Manpower identified several issues that are important to the retention of older workers including ensuring older workers have a sense of belonging, treating older workers with respect and dignity, ensuring supervisors treat everyone equally, and providing feedback to older workers on their job performance.

For employers, the challenge is how to encourage older employees to remain working within their organization. Much of the existing research on older workers focuses on their exit behavior and the factors influencing their decision to retire (Barnes-Farrell, 2003; Beehr, Glazer, Nielson, \& Farmer, 2000; Davey, 2008; Dorn and Sousa-Poza, 2007; Ekerdt, DeViney, \& Kosloski, 1996; Feldman \& Turnley, 1995; Hanisch, 1994; Mein, Martikainen, Stansfeld, Brunner, Fuhrer, \& Marmot, 2000; Shacklock and Brunetto, 2005; Taylor \& Shore, 1995). Turnover intentions and retirement intentions have some common antecedents, but turnover intentions also have a unique set of antecedents and, conversely, retirement intentions have antecedents that are separate from those for turnover intentions (Adams \& Beehr, 1998). Adams and Beehr found that work-related variables were strongly related to turnover intentions but not to retirement intentions. Schmidt and Lee (2008) found that commitment constructs differentially predicted turnover intentions and retirement intentions. These two studies demonstrated that retirement intentions and turnover intentions are two distinct forms of organizational withdrawal. The focus of our study was on organizational membership and the intention of older workers to remain a member of their organization.

Even though the aging workforce literature offers a wide array of strategies designed to retain older workers, much of this literature is atheoretical and prescriptive in nature. Shacklock, Fulop, and Hort (2007) noted that we still know relatively little about the retention of older workers and which organizational practices are most effective in encouraging older workers to stay in an organization. To address these issues, we developed and tested a conceptual model of the antecedents of older workers' intention to remain with their organization, drawing upon the theoretical framework of perceived organizational membership proposed by Masterson and Stamper (2003). According to these researchers, membership in an organization can be viewed as inclusion in a community. The perception that one is a member of that community is based on three underlying dimensions - need fulfillment, mattering, and belonging. Masterson and Stamper suggested that these underlying motives may be an important determinant of the strength of the relational ties between employees and their organizations. To maintain their membership in an organization, employees must perceive that the organization is fulfilling important needs such as economic, relatedness, or developmental needs. Mattering is the extent to which the organization provides employees with a level of influence over organizational processes and employees perceive that they matter and are valued members of the organization. The third primary motive driving employees' perceived organizational membership identified by Masterson and Stamper is belonging. The sense of belonging to an organization is based on the extent to which employees perceive that they are members of the in-group versus the out-group. Differential treatment of workers results in the perception that some employees are more valuable to the organization (insiders) whereas others are more expendable (outsiders).

In applying the perceived organizational membership framework to the context of older workers, we proposed that human resource practices tailored to the needs, preferences, and desires of older employees (need fulfillment), older workers' perception that they are making a significant contribution toward the achievement of organizational goals (mattering), and the perception that they have insider status within the organization (belonging) are important determinants of the decision of older workers to maintain their membership with their organization. The primary focus of Masterson and Stamper's study was to delineate the underlying dimensions of perceived organizational membership and to identify indicators (sub-dimensions) of need fulfillment, mattering, and belonging. They did not 
address the nature of the possible interrelationships among the dimensions/sub-dimensions except to suggest that there may be positive relationships across the dimensions/sub-dimensions and they expected the relationships between the sub-dimensions to be stronger within a dimension than across dimensions. We posited that need fulfillment and mattering would play an important role in fostering a sense of belonging which, in turn, would be related to intention to remain a member of one's organization.

\section{Conceptual model}

Our hypothesized model is shown in Figure 1. Human resource practices tailored to the needs of older employees are related to perceptions of insider status based on the way their immediate supervisor implements and manages the human resource practices. Perceived contribution to the organization is also related to perceptions of insider status which, in turn, is associated with the intention of older workers to remain with their organization.

Stamper and Masterson (2002) described how feelings of inclusion can be signaled through human resource practices. These signals induce employees to provide a return on the investment for the benefit. Accordingly, human resource practices specifically tailored to older employees will be on the radar of these employees. The existence of such practices, in combination with their just application, will signal inclusion. Moreover, the fact that these practices are specifically tailored to older workers will provide a sense of a special insider status, a privilege that will create a sense of obligation to remain. These mechanics are related to the promises and obligations inherent in the psychological contract between employees and employers (e.g., Rousseau, 1995). Rousseau and Greller (1994) posited that the main function of HRM is to foster an appropriate psychological contract and that human resource practices serve as messages senders, shaping the terms of the psychological contract.

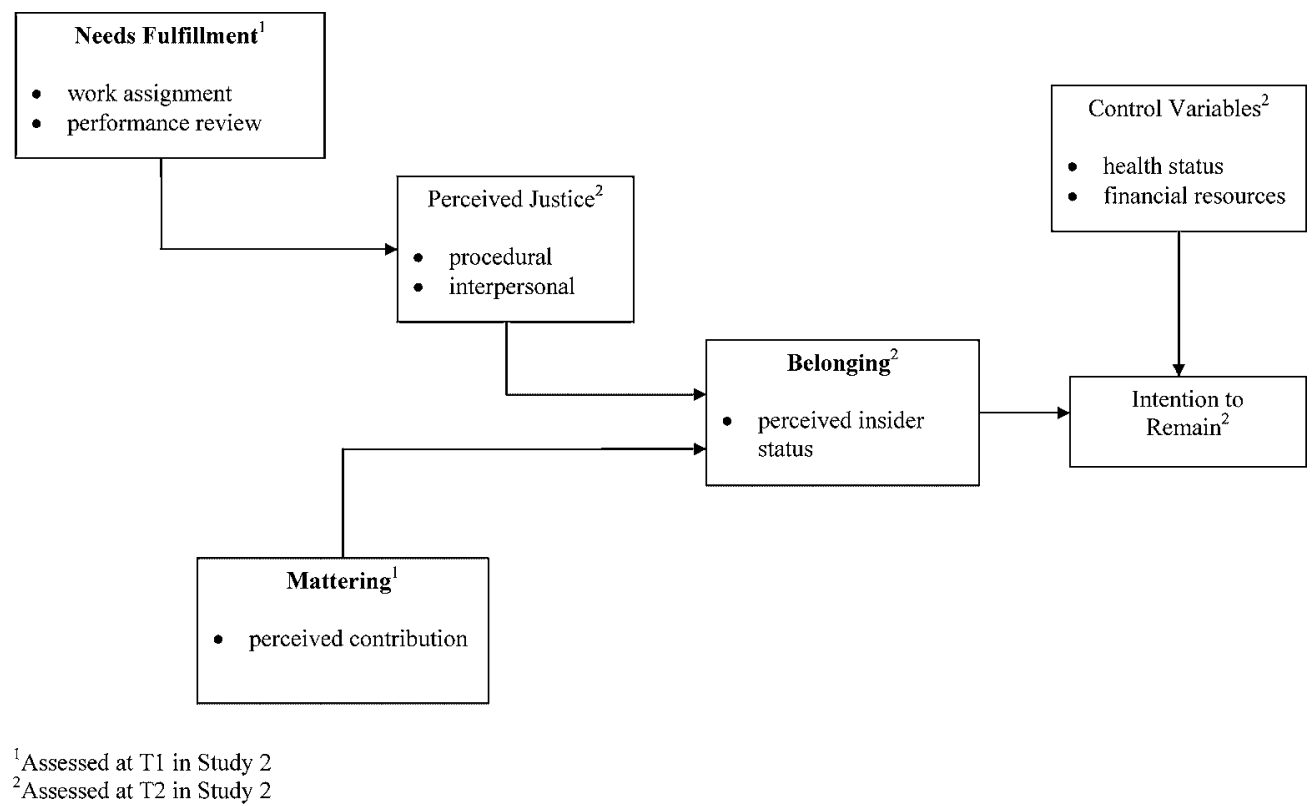

Figure 1. Conceptual model 
Most researchers have included various human resource practices when they have operationalized and measured employer responsibilities in the psychological contract between employers and employees.

Based on a review of the aging workforce literature, we identified two human resource practices that are especially relevant to addressing the needs and preferences of older workers: Work assignment practices that provide older employees with stimulating and challenging work assignments and create new work roles such as mentoring for older workers (Committee for Economic Development, 1999; Farr \& Ringseis, 2002; McEvoy \& Blahna, 2001; Meier, 1988; Mor-Barak, 1995; West \& Berman, 1996) as well as reassignment to less demanding jobs if preferred or needed (Griffiths, 1997; Hale, 1990; Hedge, Borman, \& Lammlein, 2006; Turcotte \& Schellenberg, 2005; West \& Berman, 1996), and performance review practices featuring age-neutral performance appraisals and supportive and constructive performance feedback (Callanan \& Greenhaus, 2008; Kooij, de Lange, Jansen, \& Dikkers, 2008; Patrickson, 1998, 2003; West \& Berman, 1996). Paré and Tremblay (2007) noted that human resource practices play a determining role in the development of perceived justice. There is supporting empirical evidence showing a significant relationship between employee perceptions of human resource practices and perceived fairness, especially perceived procedural justice (Edgar \& Geare, 2005; Guest, 1999; Meyer \& Smith, 2000; Paré \& Tremblay, 2007). Kuvaas (2007) argued that procedural and interactional justice perceptions are most relevant in a human resource context, i.e., the way human resource practices are implemented and the way they are administered is an important informational source of employee perceptions of both procedural and interactional justice. Accordingly, we focused on procedural justice and interpersonal justice, a dimension of interactional justice, which refers to treating people with politeness, dignity, and respect (Colquitt, 2001). We predicted that older workers employed in organizations that were engaging in work assignment and performance review practices targeted to older employees would report significantly higher levels of perceived procedural and interpersonal justice than those in organizations that did not have these practices in place.

Hypothesis 1a: Work assignment practices tailored to older workers are expected to be significantly positively related to perceived procedural and interpersonal justice.

Hypothesis 1b: Performance review practices tailored to older workers are expected to be significantly positively related to perceived procedural and interpersonal justice.

McEvoy and Blahna (2001) asked older workers to identify the least fulfilling aspects of their present job and work setting. The most frequently mentioned aspects were a lack of respect from management and a perceived reduction in status. According to the group-value model (Blader \& Tyler, 2003), both the nature of the decision-making processes and the quality of treatment convey information about one's standing in the organization. The perception that one is treated fairly promotes a sense of inclusion in the organization as well as a sense of importance to the organization whereas being treated in an unfair manner communicates one's marginal status within the organization. Research findings indicate that individuals' perceptions about the fairness of formal procedures and interpersonal treatment are important inputs into how employees judge the quality of their exchange relationships with their supervisor and organization (Masterson, Lewis, Goldman, \& Taylor, 2000). Stamper and Masterson (2002) suggested that both fair organizational procedures (procedural justice) and interpersonal treatment (interpersonal justice) within organizations may strongly influence perceptions of insider status. Kuvaas (2007) noted that although the implementation and administration of human resource practices is determined at the organizational level, it is individual supervisors who actually manage these practices. We therefore focused on how fairly older workers perceived their immediate supervisor to be in managing human resource practices specifically targeting older employees. We 
predicted that older workers who perceived that their immediate supervisor was applying human resource practices relevant to older employees fairly, i.e., in a consistent, unbiased way, would be more likely to perceive themselves as having insider status than older workers who perceived their immediate supervisor did not apply these human resource practices in a fair manner. We also predicted that older workers who perceived that their immediate supervisor treated them with respect and dignity would be more likely to perceive themselves as having insider status than older workers who felt that their immediate supervisor showed them little respect.

Hypothesis $2 a$ : Perceived procedural justice is expected to be significantly positively related to perceived insider status.

Hypothesis $2 b$ : Perceived interpersonal justice is expected to be significantly positively related to perceived insider status.

A sense of mattering reflects the perception that one makes a difference to the organization and that the organization has demonstrated that the employee does indeed matter. According to Masterson and Stamper, "to the extent that the organization provides employees with a level of influence over organizational processes, and the organization communicates to employees that they matter and are valued members, it is likely to result in greater perceptions of organizational membership" (p. 480). We used the concept of perceived meaningfulness of contribution (Brown and Leigh, 1996) to exemplify a sense of mattering. Perceived meaningfulness of contribution refers to making a significant contribution toward the achievement of organizational goals. Employees' perception that their work significantly affects organizational processes and outcomes contributes to the perceived meaningfulness of work and enhances their identification with their work role and with their organization (Brown \& Leigh, 1996). We hypothesized that the perception of being a valued member of the organization would foster a sense of belonging and the perception of being an insider in the organization.

Hypothesis 3: Perceived meaningfulness of contribution is expected to be significantly positively related to perceived insider status.

Masterson and Stamper built their arguments for perceived organizational membership based on Graham's (1991) essay on rights and responsibilities. When employees perceive themselves to be valued members of the organization, they will experience both the rights and responsibilities associated with this group membership. Perceived organizational membership reflects only the rights conferred upon the employees by the organization. The resulting obligations of employees that reflect the return on the organization's investment are equally important to the social exchange cycle. As a member of an organization, there is a responsibility to be actively present. Hence, the intention to remain working with an organization is clearly an outcome of organizational membership. Stamper and Masterson (2002) recommended that turnover intentions should be examined in conjunction with perceived insider status. Pfeffer (1985) contended that turnover occurs, at least in part, by a lack of social integration or inclusion in the organization. We therefore predicted that older workers who perceived themselves as insiders within their organization would express greater intention to remain with their organization than those who perceived themselves as outsiders. We also hypothesized that perceived insider status would mediate the relationship between the perceived justice variables and intention to remain as well as between perceived meaningfulness of contribution and intention to remain.

Hypothesis 4: Perceived insider status is expected to be significantly positively related to intention to remain. 
Hypothesis 5: Perceived insider status is expected to mediate the relationship between perceived procedural and interpersonal justice and intention to remain.

Hypothesis 6: Perceived insider status is expected to mediate the relationship between perceived meaningfulness of contribution and intention to remain.

To test the hypothesized relationships of our conceptual model, we conducted two studies. The first study was a cross-sectional study with a diverse sample of older workers aged 50-70 years. The second study was a longitudinal panel study with a sample of registered nurses aged 45 and over. We assessed the human resource practices and perceived meaningfulness of contribution at time 1 and then a year later we assessed the perceived justice, perceived insider status, and intention to remain variables.

We included health status and financial resources as control variables. Health status has been shown to have an important influence on older workers' decision to continue working. In a sample of over 2500 individuals aged 50-64, Au, Crossley, and Schellhorn (2005) found a strong positive relationship between health status and employment. Based on data from the 2003 Canadian Health Survey, Pyper (2006) found that healthy older men and women were more likely to be working than those who reported health problems. Using data from the Health and Retirement Study, researchers (Dwyer \& Mitchell, 1999; Kim \& DeVaney, 2005; McGarry, 2004; Quinn, 1999) found that health problems had a strong influence on encouraging older individuals to retire early. Financial resources have also been shown to influence older workers' decision to stay in the labor force. In a national survey of over 2500 workers aged 45-74 (AARP, 2002), three-quarters of the respondents indicated that the need for money was a major factor in their decision to continue working. Conversely, older workers with adequate financial resources are more likely to exit from the labor force (Chen \& Scott, 2006; Davey, 2008; Desmette \& Gaillard, 2008; Mermin, Johnson, \& Murphy, 2007; Parkinson, 2002).

\section{Research Context}

\section{Aging workforce in Canada}

The Conference Board of Canada (2006) identified the aging of Canada's population as one of the greatest challenges facing the country. According to Statistics Canada (2007b), the number of people aged 55-64 has never been so high with nearly one out of three Canadians being a baby-boomer in 2006. In 2003, the proportion of the Canadian working age labor force aged 45-64 increased to 40 per cent (Canadian Labour and Business Centre, 2004). The Policy Research Initiative (2005) concluded in their report on population aging and life-course flexibility that encouraging older workers to extend their working lives would help in responding to the challenges posed by the aging of Canada's population. The age of eligibility for the government-sponsored pension schemes, the Canadian Pension Plan and Old Age Security, is 65. However, many people retire well before the age of 65 . The overall median retirement age is 62 (Statistics Canada, 2004). Public sector employees retire much earlier. The median retirement age for all public sector employees is 59. For some public sector groups, especially those in education and healthcare, the median age of retirement is even lower than this.

\section{Study 1}

Study 1 was conducted in conjunction with Canada's Association for the 50 Plus (CARP). CARP is a national not-for-profit association that promotes the interests of Canada's 50 and over population, 
provides information on social and financial benefits, and interfaces with federal and provincial governments on behalf of mature Canadians. CARP's members include both people who are employed and those who have fully retired from the labor market. Those who are in the workforce represent a broad cross-section of industry sectors and a wide range of occupational categories.

\section{Study 2}

Study 2 focused on registered nurses employed in a hospital setting in the province of Ontario. Older workers will represent a greater proportion of the Canadian workforce in every occupational category, but labor shortages in the healthcare sector due to the aging of the nursing workforce are expected to be especially severe (Canadian Nursing Advisory Committee, 2002). Close to one-half of registered nurses in Canada were over 45 in 2001 and many nurses are retiring by the age of 56 (McMullin \& Cooke, 2004). Nursing shortages are also occurring in other countries including the United States (Health Resources and Services Administration, 2004), the United Kingdom (Finlayson, Dixon, Meadows, \& Blair, 2002), and Australia (O'Brien-Pallas, Duffield \& Alksnis, 2004). Simoens, Villeneuve, and Hurst (2005) reported that the majority of OECD countries are currently experiencing nurse shortages. The retention of older nurses has been suggested as a key factor in solving the nursing shortage (Hatcher, Bleich, Connolly, Davis, O'Neill Hewlett, \& Stokely Hill, 2006; O’Brien-Pallas et al., 2003; Oulton, 2006).

\section{Method}

\section{Study 1: Participants and procedure}

The data for Study 1 were collected using a web-based questionnaire. CARP placed an item on its homepage informing members that we were seeking people to participate in a study.

The item included the following:

If you are working, we want to find out what your employer is doing to encourage mature employees to stay with the organization. If you are self-employed, we are interested in what influenced your decision to become self-employed and what factors are influencing your decision to continue to work. For those of you who are retired, we want to hear how your retirement has turned out to be and what influenced your decision to retire.

For more information about this study and to complete the survey, please go to [URL http:// www.uwindsor.ca/users/m/mas/SurveyHome.nsf/ for the questionnaire home page which was on a website at the researchers' university].

When people accessed the questionnaire website, they were first instructed to read the consent form which provided detailed information about the purpose of the study, the data collection procedures, and their rights as a participant. They were then asked to click on the appropriate questionnaire box depending on whether they were employed or retired. Of those that responded, 236 were in wage-andsalary employment, 103 were self-employed, and 968 were fully retired. The focus of this paper was on the first group - people aged 50-70 who were employed in a wage-and-salary job. 
The average age of the 236 employed respondents was 59.96 years $(\mathrm{SD}=4.32)$ and they had been employed with their current organization an average of 14.10 years $(\mathrm{SD}=11.95)$. They were employed in a wide range of industries in both the private sector (e.g., construction, finance and insurance, high tech, manufacturing, wholesale, and retail) and the public sector (e.g., education, healthcare, and public administration). They also represented diverse occupations: Professional (31 per cent), management (19 per cent), sales and customer service (13 per cent), administrative and secretarial (10 per cent), and skilled trades ( 5 per cent) with 9 per cent in various other occupational categories. Fifty-one per cent were men and 49 per cent were women and 64 per cent were married.

To assess how representative our sample was, we compared it to the 2006 census data (Statistics Canada, 2007a). Because Statistics Canada uses the age categories 25-54 and 55 and over, for comparison purposes we limited our sample to respondents aged 55 and over. Statistics Canada reported that the labor force participation rate for men and women aged 55 and over was 58 and 42 per cent, respectively. For our sample, 52 per cent were men and 48 per cent were women. For sectors in which people aged 55 and over are employed, the classifications used in our study did not completely conform to those used by Statistics Canada. For example, we had healthcare as a separate classification whereas Statistics Canada combines healthcare with social services. However, we were able to make comparisons for some of the employment sectors. Statistics Canada reported that 18 per cent of those 55 and over were employed in the education sector. We also had 18 per cent of our respondents 55 and over employed in the education sector. For employment in the retail sector, the percentages were 12 per cent in our study and 13 per cent in the census data. In our study, 9 per cent were employed in the manufacturing sector versus 14 per cent in the census data. Our sample had 18 per cent employed in government and public administration versus 14 per cent in the census data. There was one sector that was under-represented in our study - construction. Only 1 per cent of our sample was employed in the construction sector versus 15 per cent in the census data.

We also compared the age and gender demographics of our total CARP sample ${ }^{1}$ with the age and gender demographics of the CARP membership. In our total sample of 1307 CARP respondents, 43 per cent were aged 50-64 (CARP membership 36 per cent), 38 per cent were 65-75 (CARP membership 39 per cent), 17 per cent were 75-84 (CARP membership 21.5 per cent), 2 per cent were 85-99 (CARP membership 3 per cent), and 0 per cent were 100+ (CARP membership .05 per cent). Approximately 60 per cent of our CARP respondents were men and 40 per cent were women compared with 55 per cent men and 45 per cent women for the CARP membership as a whole.

\section{Study 2: Participants and procedure}

We obtained a random sample of 2950 nurses aged 45 and over employed in a hospital setting from the College of Nurses of Ontario registry. We mailed questionnaire packets to these nurses in 2006 (time 1, T1) and again 12 months later in 2007 (time 2, T2). The cover letter at T1 contained the following statement: "The purpose of this research project is to identify those factors that make the workplace more attractive and therefore increase the retention of RNs aged 45 and over." The cover letter also explained that the person had been randomly selected from the College of Nurses of Ontario registry and that their participation would involve completing the enclosed questionnaire and a similar questionnaire the following year.

At T1, we received 1133 completed questionnaires, giving a response rate of 38 per cent. At T2, we received 974 questionnaires, 29 of which were later discarded because they were incomplete. We were

\footnotetext{
${ }^{1}$ Note that for this paper, we limited the sample to those aged 50-70 because very few employed respondents were over 70 years of age.
} 
contacted by 108 nurses who had retired and 11 nurses who were no longer employed in a hospital setting. In addition, 68 questionnaire packets were returned as undeliverable. Therefore, of the 2950 nurses, at least 187 were ineligible to participate at $\mathrm{T} 2$ or could no longer be reached. The response rate at $\mathrm{T} 2$ was 35 per cent. To match up T1 and T2 questionnaires, respondents were asked to provide the first four letters of their mother's first name and the last two digits of their own year of birth. It was possible to match up $528 \mathrm{~T} 1$ and $\mathrm{T} 2$ questionnaires.

We limited the matched sample to front-line nurses, excluding those nurses who were in a supervisory or management position. Because only 12 of the nurses were men, we restricted the sample to female nurses only. This resulted in a matched sample of 420 front-line registered nurses. Their average age at $\mathrm{T} 1$ was 52.20 years $(\mathrm{SD}=4.39)$ and they had been employed in their current hospital an average of 21.09 years $(S D=9.40)$ and in their present job an average of 14.81 years $(S D=10.29)$. Over 80 per cent of the respondents were represented by a labor union. Seventy-five per cent were married.

To check the representativeness of our sample, we compared our sample characteristics with the membership statistics provided by the College of Nurses of Ontario (CNO). The CNO only reports statistics for all registered nurses in the province. Except for information on the age of nurses, the statistics are not broken down by age group. Moreover, the CNO statistics are for nurses employed in all settings, e.g., hospitals, long-term care, community health agencies, whereas our sample was limited to nurses employed in a hospital setting. In our sample, 97.7 per cent were women compared with 95.4 per cent for all registered nurses in the province. For employment status, our sample characteristics are quite similar to those reported by the CNO: Full-time ( 65 per cent versus 63 per cent CNO), part-time ( 26 per cent versus 29 per cent $\mathrm{CNO}$ ), and casual ( 9 per cent versus 8 per cent $\mathrm{CNO}$ ). The CNO reported that medical/surgical (15.5 per cent) and critical care (9 per cent) ranked in the top primary areas of practice for registered nurses. In our sample, 14.3 per cent were in medical/surgical units and 9.4 per cent were in critical care units. For age groups, our sample was similar to the per cent of nurses in the 45-49 age group (28.5 per cent versus 26 per cent $\mathrm{CNO}$ ) and the 55-59 age group (22.1 per cent versus 25 per cent CNO). However, our sample had a higher proportion of nurses in the 50-54 age group (43.6 per cent versus 29.6 per cent $\mathrm{CNO}$ ) and a lower proportion in the $60-65$ age group (5.5 per cent versus 14 per cent $\mathrm{CNO}$ ).

\section{Measures}

\section{Human resource practices}

We developed a 4-item measure of work assignment practices and a 3-item measure of performance review practices for each study. For Study 1, respondents were asked to indicate to what extent their organization was currently engaging in each of the human resource practices, especially as these related to mature ${ }^{2}$ employees. The four items assessing work assignment practices were: "Providing opportunities for mature employees to take on meaningful new roles or work assignments," "Encouraging mature employees to serve as mentors," "Offering incentives to mentor others [reduced workload, additional compensation]," and "Providing a modified work role, such as reassignment to a less physically demanding job, to accommodate those who require a reduced workload." The three items assessing performance review practices were: "Conducting performance appraisals so that they fairly and accurately reflect mature employees' performance [free from age bias]," "Providing mature employees with useful feedback about their job performance," and "Providing feedback to mature employees in a supportive manner." For Study 2, the respondents were asked to indicate the extent to

\footnotetext{
${ }^{2}$ Consistent with CARP, we used the term "mature" to refer to people aged 50 and over.
} 
which their hospital was currently engaging in each of the human resource practices, especially as these related to nurses 45 and over. The four items assessing work assignment practices were: "Providing challenging and meaningful tasks or assignments to nurses 45 and over," "Creating new roles for nurses 45 and over [mentoring, put in charge of special projects]," "Reducing workload pressures and job demands when requested," and "Providing reassignment to less physically demanding jobs when requested," We assessed performance review practices with the same three items as Study 1 except we replaced the words "mature employees" with the words "nurses 45 and over." The response categories for both sets of human resource practices ranged from 1 (Not doing this at all) to 5 (Doing this a great deal).

\section{Perceived justice}

The lead-in statement for the perceived justice items asked respondents to indicate how their immediate supervisor handled human resource practices relevant to mature employees/nurses 45 and over. We assessed perceived procedural justice with six items adapted from the Procedural Justice scale developed by Colquitt (2001). A sample item is "To what extent have the procedures for implementing these practices been applied consistently by your supervisor?" Perceived interpersonal justice was measured with four items adapted from Colquitt's (2001) Interpersonal Justice scale. A sample item is "To what extent has your supervisor treated you with respect?" The response categories for both perceived justice measures ranged from 1 (To a very little extent) to 5 (To a very great extent).

\section{Perceived contribution}

We assessed respondents' perception of the meaningfulness of their contribution to their organization with the 4-item Perceived Meaningfulness of Contribution scale developed by Brown and Leigh (1996). A sample item is "The work I do is very valuable to my organization/hospital." The response categories ranged from 1 (Strongly disagree) to 5 (Strongly agree).

\section{Perceived insider status}

Perceived insider status was measured with the 6-item Perceived Insider Status scale developed by Stamper and Masterson (2002). A sample item is "I feel very much a part of this organization/ hospital." The response categories ranged from 1 (Strongly disagree) to 5 (Strongly agree).

\section{Intention to remain}

We assessed intention to remain with one's organization with five items. Three of these items were adapted from the Intent to Stay measures developed by Mueller, Wallace, and Price (1992), one item was adapted from London and Howat (1978), and one item was adapted from Lyons (1971). Sample items were "I would really hate to quit my job with this organization/hospital" and "I intend to stay with this organization/hospital until I fully retire." The response categories ranged from 1 (Strongly disagree) to 5 (Strongly agree).

\section{Control variables}

Health status was measured with the 4-item Health Status scale from Adams and Beehr (1998). A sample item is "My health is better than most people my age." We assessed financial resources with the 5-item Retirement Income Satisfaction scale developed by Adams and Beehr (1998). A sample item is "One reason I continue to work is because I can't afford to be fully retired." The response categories for both measures ranged from 1 (Strongly disagree) to 5 (Strongly agree).

\section{Demographic variables}

Study 1 respondents were asked to indicate their occupation, industry in which they were currently employed, length of time they had been employed in their current organization, their age, the age they 
planned to retire, gender, and marital status. Study 2 respondents were asked to indicate the length of time they had been employed in their current hospital, their job position, the length of time they had been employed in this job position, their age, the age they planned to retire, gender, and marital status.

\section{Data analysis}

Structural equation modeling, using LISREL 8.54 (Jöreskog \& Sörbom, 2003), was conducted to test the hypothesized model. The analysis was based on the covariance matrix and used maximum likelihood estimation. We evaluated the significance of the hypothesized paths and assessed the overall fit of the model to the data with several fit indices including the LISREL goodness-of-fit index (GFI), the adjusted goodness-of-fit index (AGFI), the root-mean-square error of approximation (RMSEA), the non-normed fit index (NNFI), and the comparative fit index (CFI). We also assessed alternative partial mediation models. The first alternative model included a direct path from work assignment practices to intention to remain. The second alternative model included a direct path from performance review practices to intention to remain. The third alternative model had a direct path added from perceived procedural justice to intention to remain. The fourth alternative model had a direct path added from perceived interpersonal justice to intention to remain. The fifth alternative model included a direct path from perceived contribution to intention to remain.

\section{Study 1: Results}

We first conducted a series of confirmatory factor analyses to establish the distinctiveness of the nine multi-item measures. The fit indices for these analyses are shown in Table 1 . The results showed that the 9-factor model fit the data significantly better than various 8-factor, 6-factor, and 1-factor models. All of the items were significantly related to their respective factor in the 9-factor model which was not the case when there were fewer than 9 factors.

Table 1. Study 1: Confirmatory factor analysis fit indices

\begin{tabular}{lcccccccc}
\hline & $\chi^{2}$ & df & GFI & AGFI & NNFI & CFI & RMSEA & $\Delta \chi^{2}$ \\
\hline 9 factors $^{2}$ & 890.26 & 732 & .82 & .79 & .99 & .99 & .03 & .06 \\
8 factors $^{\mathrm{a}}$ & 1195.28 & 740 & .77 & .73 & .98 & .98 & .96 & $305.02^{* * *}$ \\
8 factors $^{\mathrm{b}}$ & 1826.90 & 740 & .69 & .64 & .96 & .96 & .09 & $936.64^{* * *}$ \\
8 factors $^{\mathrm{c}}$ & 1048.02 & 740 & .79 & .76 & .98 & .98 & .05 & $157.76^{* * *}$ \\
8 factors $^{\mathrm{d}}$ & 1187.52 & 740 & .77 & .73 & .98 & .98 & .06 & $297.52^{* * *}$ \\
6 factors $^{\mathrm{e}}$ & 3497.06 & 753 & .53 & .47 & .90 & .91 & .14 & $3360.68^{* * *}$ \\
6 factors $^{\mathrm{f}}$ & 2940.90 & 753 & .58 & .52 & .93 & .94 & .12 & $2050.64^{* * *}$ \\
1 factor & 7755.05 & 768 & .34 & .26 & .80 & .81 & .22 & $6864.79^{* * *}$ \\
\hline
\end{tabular}

${ }^{\mathrm{a}}$ Equating work assignment practices and performance review practices.

${ }^{\mathrm{b}}$ Equating perceived procedural justice and perceived interpersonal justice.

${ }^{c}$ Equating perceived contribution and perceived insider status.

${ }^{\mathrm{d}}$ Equating perceived insider status and intention to remain.

${ }^{\mathrm{e}}$ Equating work assignment practices, performance review practices, perceived procedural justice, and perceived interpersonal justice.

${ }_{\mathrm{f}}^{\mathrm{f}}$ Equating work assignment practices, performance review practices, perceived contribution, and perceived insider status. ${ }^{* * *} p<.001$. 
Table 2. Study 1: Means, standard deviations, and zero-order correlations

\begin{tabular}{|c|c|c|c|c|c|c|c|c|c|c|}
\hline & $\operatorname{Mean}(\mathrm{SD})$ & 1 & 2 & 3 & 4 & 5 & 6 & 7 & 8 & 9 \\
\hline (1) Health status & $3.76(.89)$ & .88 & & & & & & & & \\
\hline (2) Financial resources & $2.51(1.04)$ & .01 & .89 & & & & & & & \\
\hline (3) Work assignment & $2.22(1.04)$ & -.02 & .30 & .85 & & & & & & \\
\hline (4) Performance review & $2.78(1.31)$ & .01 & .05 & .53 & .95 & & & & & \\
\hline (5) Procedural justice & $2.60(1.08)$ & -.05 & .39 & .65 & .46 & .92 & & & & \\
\hline (6) Interpersonal justice & $4.00(.95)$ & .08 & .20 & .39 & .48 & .52 & .96 & & & \\
\hline (7) Perceived contribution & $4.02(.76)$ & .11 & .21 & .41 & .30 & .41 & .28 & .84 & & \\
\hline (8) Insider status & $3.50(.96)$ & .10 & .32 & .55 & .55 & .60 & .46 & .62 & .94 & \\
\hline (9) Intention to remain & $3.68(.89)$ & .15 & .06 & .37 & .31 & .39 & .27 & .54 & .58 & .88 \\
\hline
\end{tabular}

Note: The items for each measure were summated and then averaged by dividing by the number of items in the measure. Therefore, the range for responses for each of the nine variables is 1-5. Reliability coefficients (Cronbach coefficient $\alpha$ ) are shown in bold on the diagonal. Significance levels: $r>.12, p<.05 ; r>.17, p<.01$; and $r>.21, p<.001$.

The means, standard deviations, and zero-order correlations are shown in Table 2. Both human resource practices were significantly positively related to perceived procedural and interpersonal justice and the perceived justice variables and perceived contribution were significantly positively related to perceived insider status. Perceived insider status was significantly positively related to intention to remain. There were few significant correlations between the demographic variables and the study variables. There was a weak positive relationship $(r=.13)$ between age and intention to remain as well as a weak positive relationship $(r=.14)$ between planned retirement age and intention to remain. Regression analyses showed that neither age nor planned retirement age was a significant predictor of intention to remain.

\section{Study 1: Overall fit of the hypothesized and alternative models}

The fit indices for the hypothesized model and the alternative models for Study 1 are presented in Table 3. A model is considered to have a good fit to the data when the GFI, AGFI, NNFI, and CFI fit

Table 3. Study 1: Fit indices for the hypothesized and alternative models

\begin{tabular}{lccccccc}
\hline & $\chi^{2}$ & df & GFI & AGFI & NNFI & CFI & RMSEA \\
\hline Hypothesized model $^{\mathrm{a}}$ & 936.23 & 747 & .81 & .78 & .99 & .99 & .04 \\
Alternative Model 1 $^{\mathrm{b}}$ & 934.60 & 746 & .81 & .78 & .99 & .99 & .04 \\
Alternative Model 2 $^{\mathrm{c}}$ & 933.77 & 746 & .81 & .78 & .99 & .99 & .04 \\
Alternative Model 3 $^{\mathrm{d}}$ & 934.68 & 746 & .81 & .78 & .99 & .99 & .04 \\
Alternative Model 4 $^{\mathrm{e}}$ & 934.28 & 746 & .81 & .78 & .99 & .99 & .04 \\
Alternative Model 5 $^{\mathrm{f}}$ & 918.53 & 746 & .81 & .79 & .99 & .99 & .03 \\
\hline
\end{tabular}

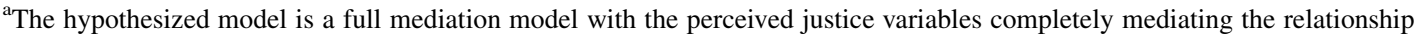
between the human resource practices and perceived insider status, and perceived insider status completely mediating the relationship between the perceived justice variables and perceived contribution and intention to remain.

${ }^{b}$ Model 1 is a partial mediation model with a direct path added between work assignment practices and intention to remain. This path was not significant.

${ }^{c}$ Model 2 is a partial mediation model with a direct path added between performance review practices and intention to remain. This path was not significant.

${ }^{\mathrm{d}}$ Model 3 is a partial mediation model with a direct path added between perceived procedural justice and intention to remain. This path was not significant.

${ }^{\mathrm{e}}$ Model 4 is a partial mediation model with a direct path added between perceived interpersonal justice and intention to remain. This path was not significant.

${ }^{\mathrm{f}}$ Model 5 was a partial mediation model with a direct path added between perceived contribution and intention to remain. This path was significant. 
indices have a value of .90 or higher and the RMSEA has a value lower than .08 (Kelloway, 1998). Although the GFI and AGFI were below .90, the NNFI, CFI, and RMSEA fit indices showed that the hypothesized model had an acceptable fit to the data.

The alternative models we tested had direct paths added between work assignment practices (model 1), performance review practices (model 2), perceived procedural justice (model 3), perceived interpersonal justice (model 4), and perceived contribution (model 5) and intention to remain. In models $1-4$, the added paths were not significant. However, in model 5 the direct path between perceived contribution and intention to remain was significant indicating that the relationship between perceived contribution and intention to remain was both direct as well as indirect through perceived insider status.

\section{Study 1: Hypothesized relationships among variables}

The maximum likelihood unstandardized and standardized (in brackets) parameter estimates for the hypothesized model with the additional path between perceived contribution and intention to remain are shown in Figure 2. Work assignment practices was significantly positively related to perceived procedural justice and perceived interpersonal justice, confirming hypothesis 1a. There was only partial support for hypothesis $1 \mathrm{~b}$. Performance review practices was significantly positively related to perceived interpersonal justice but the relationship between performance review practices and perceived procedural justice was not significant. Consistent with hypotheses $2 \mathrm{a}$ and $2 \mathrm{~b}$, both perceived procedural and interpersonal justice were significantly positively related to perceived insider status. Perceived contribution was significantly positively related to perceived insider status, confirming hypothesis 3 . Perceived insider status was significantly positively related to intention to remain, supporting hypothesis 4 . The direct paths between perceived procedural and interpersonal justice and intention to remain were not significant indicating that perceived insider status fully mediated the relationship between the perceived justice variables and intention to remain, confirming hypothesis 5 . Hypothesis 6 predicted that perceived insider status would mediate the relationship between perceived contribution and intention to remain. There was evidence of the indirect effect of perceived

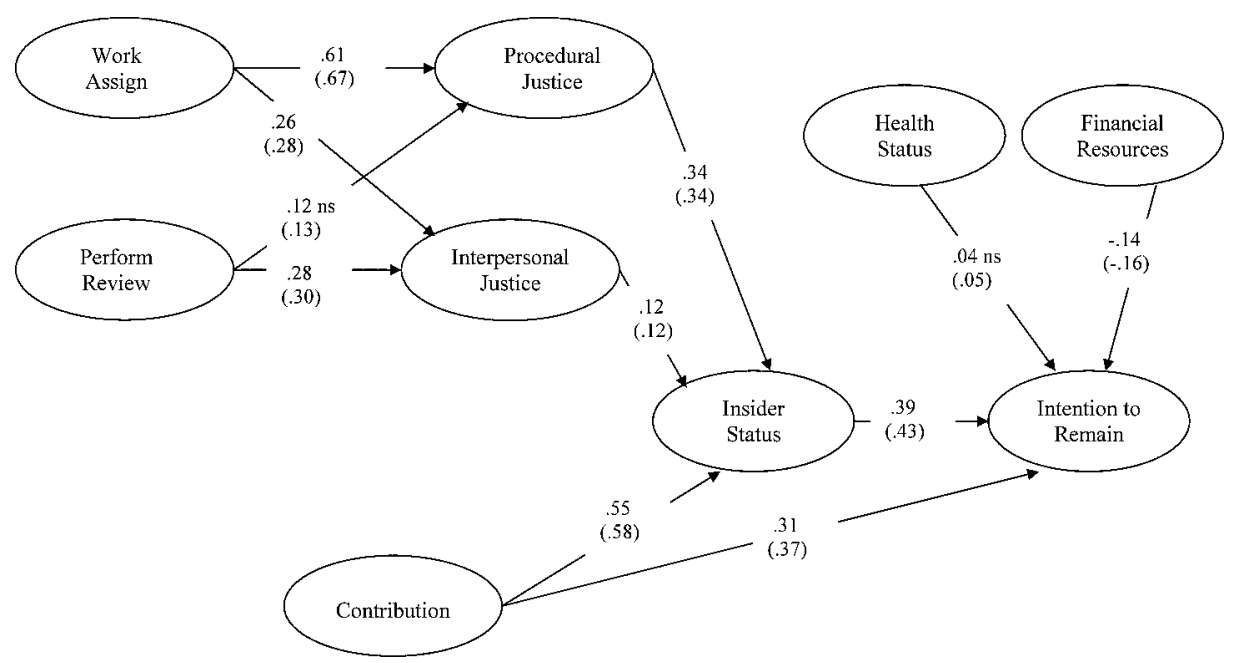

Figure 2. Study 1 parameter estimates for the modified hypothesized model 
contribution on intention to remain through perceived insider status. The test of the hypothesized model showed that the path between perceived contribution and perceived insider status was significant as was the path between perceived insider status and intention to remain. However, alternative Model 5 showed that, in addition to the indirect effect through perceived insider status, the direct path between perceived contribution and intention to remain remained significant indicating that the relationship between perceived contribution and intention to remain was only partially mediated by perceived insider status.

The squared multiple correlation indicates the strength of a linear relationship. It is interpreted in the same way that $R^{2}$ is in a regression equation. The squared multiple correlations for the relationships among the human resource practices and perceived justice were .58 for procedural justice and .28 for interpersonal justice. The squared multiple correlation for the relationship between the justice variables and perceived contribution and perceived insider status was .73. Finally, the squared multiple correlation for the relationship between perceived insider status and intention to remain, including the control variables, was .53 . The total effect of work assignment practices on perceived insider status (.24) was stronger than the total effect of performance review practices on perceived insider status (.07). The total effect of procedural justice on intention to remain (.13) was stronger than the total effect of interpersonal justice on intention to remain (.05).

\section{Study 2: Results}

We conducted confirmatory factor analyses to establish the distinctiveness of the nine multi-item measures. The fit indices for these analyses are shown in Table 4. The results showed that the 9-factor model fit the data significantly better than various 8-factor, 6-factor, and 1-factor models.

The means, standard deviations, and zero-order correlations are shown in Table 5. The work assignment practices and performance review practices assessed at $\mathrm{T} 1$ were significantly positively related to perceived procedural and interpersonal justice at T2. Both perceived procedural and interpersonal justice were significantly positively associated with perceived insider status. Perceived contribution, also assessed at T1, was significantly positively related to perceived insider status at T2.

Table 4. Study 2: Confirmatory factor analysis fit indices

\begin{tabular}{lrccccccc}
\hline & \multicolumn{1}{c}{$\chi^{2}$} & df & GFI & AGFI & NNFI & CFI & RMSEA & $\Delta \chi^{2}$ \\
\hline 9 factors $^{\mathrm{a}}$ & 828.10 & 729 & .89 & .87 & .99 & .99 & .02 & .04 \\
8 factors $^{\mathrm{a}}$ & 1046.68 & 737 & .86 & .84 & .98 & .98 & .98 & $218.58^{* * *}$ \\
8 factors $^{\mathrm{b}}$ & 1644.72 & 737 & .80 & .77 & .95 & .96 & .06 & $816.62^{* * *}$ \\
8 factors $^{\mathrm{c}}$ & 938.14 & 737 & .88 & .86 & .98 & .98 & .03 & $110.04^{* * *}$ \\
8 factors $^{\mathrm{d}}$ & 1088.69 & 737 & .86 & .84 & .98 & .98 & .04 & $260.59^{* * *}$ \\
6 factors $^{\mathrm{e}}$ & 3012.19 & 750 & .69 & .64 & .89 & .90 & .10 & $2184.09^{* * *}$ \\
6 factors $^{\mathrm{f}}$ & 1994.64 & 750 & .77 & .73 & .94 & .94 & .07 & $1166.54^{* * *}$ \\
1 factor & 6315.61 & 765 & .51 & .45 & .78 & .79 & .15 & $5487.51^{* * *}$ \\
\hline
\end{tabular}

${ }^{a}$ Equating work assignment practices and performance review practices.

${ }^{\mathrm{b}}$ Equating perceived procedural justice and perceived interpersonal justice.

${ }^{c}$ Equating perceived contribution and perceived insider status.

${ }^{\mathrm{d}}$ Equating perceived insider status and intention to remain.

${ }^{\mathrm{e}}$ Equating work assignment practices, performance review practices, perceived procedural justice and perceived interpersonal justice.

${ }^{\mathrm{f}}$ Equating work assignment practices, performance review practices, perceived contribution, and perceived insider status. ${ }^{* * *} p<.001$. 
Table 5. Study 2: Means, standard deviations, and zero-order correlations

\begin{tabular}{lllllllllll}
\hline & Mean(SD) & 1 & 2 & 3 & 4 & 5 & 6 & 7 & 8 & 9 \\
\hline (1) Health status & $3.77(.82)$ &. $\mathbf{8 7}$ & & & & & & & & \\
(2) Financial resources & $2.31(.85)$ & .07 & $\mathbf{. 8 6}$ & & & & & & \\
(3) Work assignment & $2.08(.69)$ & .07 & .06 &. $\mathbf{7 6}$ & & & & & \\
(4) Performance review & $2.25(1.04)$ & .01 & .07 & .40 &. $\mathbf{9 2}$ & & & & \\
(5) Procedural justice & $1.92(.85)$ & .05 & .10 & .31 & .31 & $\mathbf{. 2}$ & & & \\
(6) Interpersonal justice & $3.54(1.12)$ & .13 & .11 & .20 & .24 & .52 & $\mathbf{. 9 6}$ & & & \\
(7) Perceived contribution & $4.05(.66)$ & .12 & .11 & .22 & .24 & .20 & .19 &. $\mathbf{7 0}$ & & \\
(8) Insider status & $3.19(.76)$ & .14 & .18 & .25 & .27 & .41 & .46 & .31 &. $\mathbf{9 1}$ & \\
(9) Intention to remain & $3.59(.75)$ & .12 & .10 & .11 & .27 & .32 & .32 & .22 & .59 & $\mathbf{. 8 7}$ \\
\hline
\end{tabular}

Note: The items for each measure were summated and then averaged by dividing by the number of items in the measure. Therefore, the range for responses for each of the nine variables is 1-5. Reliability coefficients (Cronbach coefficient $\alpha$ ) are shown in bold on the diagonal. Significance levels: $r>.10, p<.05 ; r>.13, p<.01$; and $r>.15, p<.001$.

Perceived insider status was significantly positively related to intention to remain with one's hospital. As in Study 1, there were few significant correlations between the demographic variables and the study variables including near-zero correlations between age and intention to remain $(r=.02)$ and between planned retirement age and intention to remain $(r=.03)$.

\section{Comparisons of Study 1 and Study 2 respondents}

Compared with the Study 1 respondents, the nurses in Study 2 were significantly younger $\left(t_{(654)}=18.61, p<.001\right)$, had significantly more organizational tenure $\left(t_{(649)}=-8.10, p<.001\right)$ and job tenure $\left(t_{(650)}=-7.70, p<.001\right)$, and planned to retire at a significantly younger age $(M=67.92$ versus $\left.M=60.57 ; t_{(595)}=14.11, p<.001\right)$. For the control variables, there was no significant difference between the two groups for health status $\left(t_{(648)}=-.14, p>.05\right)$. However, older nurses reported significantly fewer financial resources than older workers in Study $1\left(t_{(647)}=2.67, p<.01\right)$. For the major study variables, there were no significant differences between the two groups of respondents for perceived contribution $\left(t_{(645)}=-.45, p>.05\right)$ and intention to remain with one's organization $\left(t_{(694)}=1.23, p>.05\right)$. There were significant differences for the other variables. Study 1 respondents indicated that their organization was more likely to be engaging in the performance review practices $\left(t_{(632)}=5.62, p<.001\right)$, perceived their immediate supervisor to be treating them more fairly (procedural justice $t_{(572)}=8.27, p<.001$; interpersonal justice $\left(t_{(627)}=5.25, p<.001\right)$, and were significantly more likely to perceive themselves as having insider status $\left(t_{(641)}=4.54, p<.001\right)$ than the Study 2 respondents. We did not conduct a comparison for work assignment practices because of the differences in how this variable was assessed in the two studies.

\section{Study 2: Overall fit of the hypothesized and alternative models}

The fit indices for the hypothesized model and the five alternative models for Study 2 are presented in Table 6. The fit indices showed that the hypothesized model had an acceptable fit to the data. We also tested a series of alternative models with a direct path added between work assignment practices (Model 1), performance review practices (Model 2), perceived procedural justice (Model 3), perceived interpersonal justice (Model 4), and perceived contribution (Model 5) and intention to remain. 
Table 6. Study 2: Fit indices for the hypothesized and alternative models

\begin{tabular}{lccccccc}
\hline & $\chi^{2}$ & df & GFI & AGFI & NNFI & CFI & RMSEA \\
\hline Hypothesized model $^{\mathrm{a}}$ & 860.11 & 744 & .89 & .87 & .99 & .99 & .02 \\
Alternative Model 1 $^{\mathrm{b}}$ & 855.85 & 743 & .89 & .87 & .99 & .99 & .02 \\
Alternative Model 2 $^{\mathrm{c}}$ & 860.25 & 743 & .89 & .87 & .99 & .99 & .02 \\
Alternative Model 3 $^{\mathrm{d}}$ & 859.35 & 743 & .89 & .87 & .99 & .99 & .02 \\
Alternative Model 4 $^{\mathrm{e}}$ & 860.51 & 743 & .89 & .87 & .99 & .99 & .02 \\
Alternative Model 5 $^{\mathrm{f}}$ & 860.41 & 743 & .89 & .87 & .99 & .99 & .02 \\
\hline
\end{tabular}

${ }^{a}$ The hypothesized model is a full mediation model with the perceived justice variables completely mediating the relationship between the human resource practices and perceived insider status, and perceived insider status completely mediating the relationship between the perceived justice variables and perceived contribution and intention to remain. ${ }^{\mathrm{b}}$ Model 1 is a partial mediation model with a direct path added between work assignment practices and intention to remain. This path was not significant. ${ }^{c}$ Model 2 is a partial mediation model with a direct path added between performance review practices and intention to remain. This path was not significant. ${ }^{\mathrm{d}}$ Model 3 is a partial mediation model with a direct path added between perceived procedural justice and intention to remain. This path was not significant. ${ }^{e}$ Model 4 is a partial mediation model with a direct path added between perceived interpersonal justice and intention to remain. This path was not significant. ${ }^{\mathrm{f}}$ Model 5 was a partial mediation model with a direct path added between perceived contribution and intention to remain. This path was not significant.

Although the alternative models had similar fit indices as the hypothesized model, none of these added paths was significant.

\section{Study 2: Hypothesized relationships among variables}

The maximum likelihood unstandardized and standardized (in brackets) parameter estimates for the hypothesized model are shown in Figure 3. Consistent with hypotheses 1a and 1b, work assignment practices and performance review practices were each significantly positively related to perceived

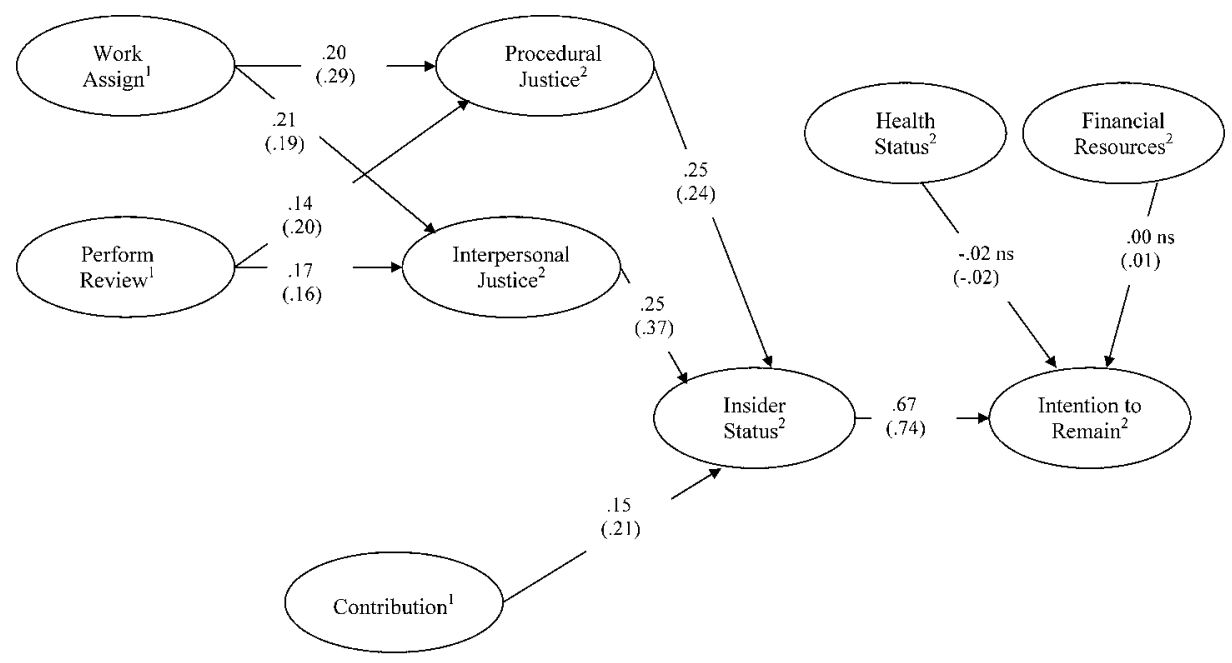

\footnotetext{
${ }^{\mathrm{I}}$ Assessed at $\mathrm{Tl}$
}

${ }^{2}$ Assessed at T2

Figure 3. Study 2 parameter estimates for the hypothesized model 
procedural and interpersonal justice. Perceived procedural justice and perceived interpersonal justice were significantly positively related to perceived insider status, supporting hypotheses $2 \mathrm{a}$ and $2 \mathrm{~b}$. Perceived contribution was significantly positively related to perceived insider status (hypothesis 3 ) and perceived insider status was significantly positively related to intention to remain (hypothesis 4). The direct paths between perceived procedural and interpersonal justice and intention to remain were not significant indicating that perceived insider status fully mediated the relationship between the perceived justice variables and intention to remain, confirming hypothesis 5 . The direct path between perceived contribution and intention to remain was not significant indicating that perceived insider status also fully mediated this relationship, supporting hypothesis 6 .

The squared multiple correlations for the relationships among the human resource practices and perceived justice were .19 for procedural justice and .09 for interpersonal justice. The squared multiple correlation for the relationship between the justice variables and perceived contribution and perceived insider status was .37. The squared multiple correlation for the relationship between perceived insider status and intention to remain, including the control variables, was .55. The total effect of work assignment practices on perceived insider status (.10) was similar to the total effect of performance review practices on perceived insider status (.08). Procedural justice and interpersonal justice had an identical total effect of .17 on intention to remain.

To examine measurement invariance across the two studies, we conducted a series of nested confirmatory factor analytic models using multiple-groups covariance structural modeling. The study variables were assessed with identical items across the two studies except for the work assignment items. Our analysis of measurement invariance was therefore limited to partial measurement invariance (Byrne, 1998, p. 269) because the factor loadings and error variances for work assignment were allowed to vary, i.e., not constrained equal, across the two groups in all CFA models. With this exception, the remaining estimated parameters were tested for invariance across the CARP and nursing samples.

The baseline model assumed no measurement equivalence across the two groups. For this model, factor loadings and error variances were freely estimated for each group. The fit statistics for the baseline model were $\chi^{2}=2266.91, \mathrm{df}=1558, \mathrm{GFI}=.86, \mathrm{NNFI}=.98, \mathrm{CFI}=.98, \mathrm{SRMR}=.09$, and RMSEA $=.04$. In the second model (Model 2), factor loadings, except for work assignment, were constrained as equal across the two groups but the error variances remained free. The fit statistics for this model were $\chi^{2}=2320.42, \mathrm{df}=1587, \mathrm{GFI}=.86, \mathrm{NNFI}=.98, \mathrm{CFI}=.98, \mathrm{SRMR}=.10$, and RMSEA $=.04$. In the third model (Model 3), error variances were constrained equal across the two groups but the factor loadings remained free. The fit statistics for this model were $\chi^{2}=2262.56$, $\mathrm{df}=1558, \mathrm{GFI}=.86, \mathrm{NNFI}=.98, \mathrm{CFI}=.98, \mathrm{SRMR}=.09$, and RMSEA $=.04$. In the fourth model (Model 4), both factor loadings and error variances were constrained to be equal across the two groups. The fit statistics for this model were $\chi^{2}=2320.42, \mathrm{df}=1587, \mathrm{GFI}=.86, \mathrm{NNFI}=.98, \mathrm{CFI}=.98$, $\mathrm{SRMR}=.10$, and RMSEA $=.04$. There was a significant difference between the baseline model and the models with the factor loadings constrained to be equal across the two groups (difference in $\left.\chi^{2}=53.51, \mathrm{df}_{\mathrm{diff}}=29, p<.01\right)$.

Vandenberg and Lance (2001) argued that the $\chi^{2}$ test of model fit should be interpreted in conjunction with other fit indices. The other fit indices were highly similar across the four models and are indicative of a relatively good fit of the model to the data. However, in examining the difference between a more restricted model and a less restricted model, Vandenberg and Lance (2001, p. 45) recommended that researchers rely on the $\chi^{2}$ difference procedure as the primary means for evaluating model differences. The significant $\chi^{2}$ difference between the baseline model and Models 2 and 4 suggest that the factor loadings are not equivalent across the two studies. This precludes testing for structural invariance, i.e., equality of structural paths across the two groups (Vandenberg \& Lance, 2001). 


\section{Discussion}

A major contribution of this paper is the application of the perceived organizational membership framework to the context of older workers. Using two studies, we demonstrated empirically the relevance of the indicators of need fulfillment, mattering, and belonging to the intention of older workers to remain with their organization. Specifically, we found that older workers were more likely to perceive themselves as having insider status (belonging) and, in turn, intend to remain with their organization when their organization was perceived to be providing human resource practices tailored to the needs, preferences, and desires of older employees (need fulfillment) and their supervisor was perceived to be managing human resource practices targeting older employees fairly (procedurally and interpersonally) and when older workers perceived that they were making a meaningful contribution to their organization's goals (mattering).

The findings also supported our proposed interrelationships among the three dimensions of perceived organizational membership, i.e., need fulfillment and mattering foster a sense of belonging. In Study 1, human resource practices, perceived contribution, and perceived insider status were assessed at the same time so even though the structural equation modeling results showed support for the hypothesized relationships there is a concern about the cross-sectional nature of the data. However, in Study 2, we assessed the human resource practices and perceived contribution one year prior to assessing perceived insider status and therefore the findings of this longitudinal study provide stronger support for the hypothesized relationships. Stamper and Masterson (2002) suggested that "the organizational justice literature may provide some additional insight into how employees develop perceptions of insider status" and that "both fair organizational procedures and interpersonal treatment within organizations may be strong influences on PIS" (p. 891). Our findings indicated that perceived procedural justice and perceived interpersonal justice associated with the way supervisors manage human resource practices targeted to older employees are important in fostering perceptions of insider status among older workers.

The pattern of path relationships was relatively similar in both studies and supported the hypothesized model even though the two samples were quite different providing support for the generalizability of the conceptual model to diverse groups of older workers. There were only two differences in the structural path relationships between the two studies. In Study 1, the hypothesized relationship between performance review practices and perceived procedural justice was not significant and perceived insider status partially mediated the relationship between perceived contribution and intention to remain whereas in Study 2 the hypothesized relationship between performance review practices and perceived procedural justice was supported and perceived insider status fully mediated the relationship between perceived contribution and intention to remain. This latter difference is shown in Figure 2 with the addition of the direct path between perceived contribution and intention to remain. The test of partial measurement invariance showed that the two groups were not equivalent, i.e., the factor loadings of the latent variables differed across the two studies, and we were unable to proceed with a test of the equivalence of the structural factors (Vandenberg \& Lance, 2001). Therefore, even though there was similarity in the pattern of path relationships, there were measurement differences across the two groups.

Although there was general support for the hypothesized model, there were some differences in the magnitude of the coefficients for relationships and the strength of relationships as indicated by the squared multiple correlations. With the exception of the relationship between performance review practices and perceived procedural justice, the magnitude of the relationships between the human resource practices and the perceived justice variables was stronger and the human resource practices accounted for more of the variance in the perceived justice variables in Study 1 compared to Study 2 (58 per cent versus 19 per cent for perceived procedural justice and 28 per cent versus 9 per cent for 
perceived interpersonal justice). The magnitude of the relationship between perceived contribution and perceived insider status was also stronger in Study 1 than in Study 2. The perceived justice variables and perceived contribution accounted for more of the variance in perceived insider status in Study 1 compared to Study 2 (73 per cent and 37 per cent, respectively). However, perceived insider status accounted for slightly more of the variance in intention to remain in Study 2 (55 per cent) compared with Study 1 (49 per cent without the added perceived contribution path). One possible explanation for the stronger relationships in Study 1 is that all variables in Study 1 were assessed at the same time which may have inflated these relationships. In Study 2, the human resource practices and perceived contribution were assessed one year prior to the assessment of the other variables. What is noteworthy, however, is that even with this 1-year interval all of the hypothesized relationships between the human resource practices and perceived contribution and the other variables were significant in Study 2. Another possible explanation for the differences in the magnitude of the coefficients for the relationships between work assignment practices and the perceived justice variables is the different measures that were used in the two studies to assess work assignment practices. It is also possible that the interrelationship of the measure of work assignment practices with the other human resource practice, performance review, may have affected the hypothesized relationships. There was a stronger correlation between work assignment practices and performance review practices in Study 1 than in Study 2.

An examination of those variables in Study 2 that were assessed at T2 showed that the magnitude of the coefficient for the perceived procedural justice and perceived insider status relationship was slightly higher in Study 1 compared with Study 2 but the total effect of procedural justice on intention to remain was slightly higher in Study 2. On the other hand, the magnitude of the coefficient for the relationship between perceived interpersonal justice and perceived insider status was stronger in Study 2 than in Study 1 and the total effect of the relationship between perceived interpersonal justice and intention to remain was significant for Study 2 but not for Study 1. These findings suggest that being treated with respect and dignity by one's immediate supervisor is more important in fostering perceived insider status among nurses than older workers in general. At the same time, how fairly one's immediate supervisor implements human resource practices tailored to older employees is less important for nurses than older workers in general. Most of the nurses in the province, especially those employed in a hospital setting, are represented by a labor union so their supervisors have clearly defined rules to follow and therefore have less discretion in how practices are administered. The magnitude of the coefficient for the relationship between perceived insider status and intention to remain was stronger in Study 2 compared with Study 1. This suggests that a sense of inclusion and belonging is especially important to the retention of older nurses.

\section{Practical implications}

There are numerous studies in the aging workforce literature advancing a myriad of human resource practices designed to promote the retention of older workers. Our findings suggest that to retain their older employees organizations should be engaging in human resource practices tailored to the needs of older workers. But what may be even more critical to the retention of older employees is that supervisors are perceived to be administering these practices fairly. Not only should organizations invest in educating supervisors on the importance of applying human resource practices targeting older employees in a fair manner and treating older employees with respect and dignity, but also making supervisors aware of the needs and preferences of older workers.

The results also demonstrated the importance of creating conditions that optimize older workers' perceptions of making a meaningful contribution to the organization. Some ways of accomplishing this include providing older employees with challenging work assignments that make a difference, creating 
mentoring opportunities that give older employees the opportunity to pass along their knowledge, skills, and expertise to younger employees, and recognizing both formally and informally the contribution of older employees.

\section{Limitations}

A major limitation of the two studies is the exclusive reliance on self-reported measures. Especially for Study 1, the cross-sectional research design and the self-report data leave the findings open to the criticism of common method variance. The confirmatory factor analysis indicated the independence of the multi-item measures in both studies. In general, the SEM results were consistent with the hypothesized model and the different pattern of relationships together with the non-significance of all but one of the added paths in the alternative models suggest that common method bias did not play a major role. We were unable to supply a response rate for the web questionnaires in Study 1 making the representativeness of the Study 1 sample an issue. We did take steps to try to verify the representativeness of this sample by making demographic comparisons with census data as well as with the overall CARP membership. The high proportion of unionized registered nurses employed in a hospital setting may limit the generalizability of the findings. For example, nurses in other employment settings in Canada, such as community health care and long-term care, are less likely to be represented by a union and registered nurses employed in a hospital setting in other countries such as the United States are also much less likely to be unionized than their Canadian counterparts. We relied on respondents' perceptions of the human resource practices their organization had in place. It is possible that respondents may not always be aware of specific human resource practices their organization is providing. An objective assessment of an organization's human resource practices targeting older workers would be useful in confirming the accuracy of older workers' perceptions of their organization's practices. This would be feasible if a study involves older workers from one or only a few organizations but would be quite difficult to do in our case when the older workers were from a large number of organizations across a wide geographical area. All of the major variables were assessed using the same items except for work assignment practices. Because of the use of different measures for work assignment practices, the findings of the two studies cannot be directly compared.

From the wide array of human resource practices identified in the aging workforce literature, we chose to focus on work assignment practices and performance review practices. However, there are other human resource practices targeting the needs, preferences, and desires of older workers that warrant consideration as indicators of the need fulfillment dimension. For example, Masterson and Stamper identified person-organization fit as a sub-dimension of needs fulfillment. Personorganization fit occurs when the organization satisfies an individual's needs or when an individual has the abilities required to meet the organization's needs. Ng and Feldman (2007) proposed that fit for older workers revolves around skill updating, retraining, and professional development. Older workers are more likely to experience plateauing and skill obsolescence than their younger counterparts resulting in greater intention to leave their organization (Allen, Poteet, \& Russell, 1998; Choy \& Savery, 1998). One way to meet the needs of older workers so that they avoid plateauing and skill obsolescence is to provide them with access to training and development opportunities to upgrade their current skills or to acquire new skills, to encourage them to participate in learning activities, and to reward them for using newly acquired knowledge and skills on the job.

In Study 2, except for $\chi^{2}$, the fit indices for the alternative models were equal to the fit indices for the hypothesized model. Equivalent models are alternative models that fit the data equally well but offer differing significance in theoretical interpretation (Henley, Shook, \& Peterson, 2006). Goodness-of-fit indices alone cannot be used to support a model when there is an equivalent model because there are no 
differences in the fit statistics between the hypothesized model and the alternative model. In this case, the significance and interpretability of the parameters can be used to support one model over another (Henley et al., 2006). The alternative models were partial mediation models, including both direct and indirect paths. None of the direct paths was significant providing support for the full mediation hypothesized model. The hypothesized model is also supported on the grounds that it is the most parsimonious model. According to Kelloway (1998, p. 10), "In general, we are striving for the most parsimonious diagram that (a) fully explains why variables are correlated and (b) can be justified on theoretical grounds."

Although the pattern of significant paths across Study 1 and Study 2 was quite similar supporting the hypothesized model, generalizability of the findings also depends on how representative respondents were of their respective populations. When compared to Canadian workers aged 55 and above for gender and industry sectors, our Study 1 respondents were shown to be reasonably representative except for the under-representation of workers in the construction industry. The age and gender of the respondents was also reasonably representative of the CARP membership. For Study 2, our respondents' characteristics in regard to gender, employment status, and primary areas of practice were quite similar to the demographic characteristics of all registered nurses in the province. The per cent of nurses aged 45-49 and 55-59 was also similar to the provincial percentages. However, the per cent of nurses aged 50-54 was higher than the provincial percentage and the per cent of nurses aged 60-65 was lower than the provincial percentage. The fact that the College of Nurses of Ontario membership statistics are based on registered nurses employed in all healthcare settings and not just hospitals may account for at least some of the discrepancy for the age distributions. There is a tendency for nurses 60 and over to leave hospital employment for employment in healthcare agencies where the job duties are less physically demanding and the work environment is less stressful. These comparisons provide some, albeit limited, evidence for the representativeness of each study's respondents and the generalizability of the findings.

\section{Future research}

Further research is needed to refine the links between perceived organizational membership and intention to remain. For example, engagement may play a mediating role between perceived insider status and intention to remain. Frank, Finnegan, and Taylor (2004) noted that employee engagement is closely linked to employee retention. Saks (2006) found that both job engagement and organization engagement were significantly negatively related to intention to quit. Based on social exchange theory and the norm of reciprocity, Saks proposed that one way for individuals to repay their organization is through their level of engagement. Engagement may be especially relevant to the context of older workers. Pitt-Catsouphes and Matz-Costa (2008) argued that, "The engagement of older workers deserves particular attention, in part, because it has long been assumed that it was normative for workers to become disengaged from their work as they get older" (p. 216).

In an effort to clarify the meaning of employee engagement, Macey and Schneider (2008) identified three types of engagement - trait engagement (e.g., proactive personality), state engagement (e.g., affective commitment and job involvement), and behavioral engagement (e.g., role expansion and adaptive behavior). The negative relationship between affective commitment and turnover intentions is well documented (Cooper-Hakim \& Viswesvaran, 2005). According to Cho and Mor Barak (2008), the more employees feel that they are in the in-group, the more they are committed to their organizations. Therefore, it is plausible that affective commitment mediates the relationship between perceived insider status and intention to remain. However, behavioral engagement may be especially relevant as an outcome of older workers' perceived organizational membership. Macey and Schneider proposed 
that behavioral engagement is adaptive behavior intended to serve an organizational purpose. Based on social exchange theory and the norm of reciprocity, older workers who perceive the organization is meeting their needs, who feel their organization values their contribution, and who perceive they have insider status are more likely to exhibit behavioral engagement behavior than those with a weaker employee-organizational membership.

The retention of older workers is currently a challenge for some employers, especially those in the healthcare sector, and will become increasingly problematic for others in the near future. We used an innovative approach to older worker retention by incorporating the group-value theory from the justice literature into the relatively new, and to our knowledge, untested perceived organizational membership framework to identify antecedents of older workers' intention to remain with their organization. The two studies, for the most part, provided empirical support for the hypothesized model and the viability of viewing the retention of older workers in terms of need fulfillment, mattering, and belonging. Older workers will want to remain with an organization that creates a sense of belonging by providing human resource practices that meet their needs, ensuring supervisors implement these practices fairly, and making older workers feel that their contribution is valued. Future research, however, is needed to further test the conceptual model and to refine linkages among the key variables.

\section{Acknowledgements}

These studies were funded by a grant (410-2005-0046) from the Social Sciences and Humanities Research Council of Canada.

\section{Author biographies}

Marjorie Armstrong-Stassen is Professor Emeritus of Management at the Odette School of Business, University of Windsor, Canada. Her research interests are in the areas of the aging of the workforce, organizational downsizing, and layoff survivors. Her current research focuses on the role of organizational policies and practices in the retention of mature employees.

Francine Schlosser is an Associate Professor of Management at the Odette School of Business, University of Windsor, Canada. Her research examines individual and interpersonal factors influencing strategy related to marketing, human resources, and entrepreneurship.

\section{References}

AARP. (2002). Staying Ahead of the Curve: The AARP Work and Career Study. Retrieved on November 20, 2002 from http://www.aarp.org

Adams, G. A., \& Beehr, T. A. (1998). Turnover and retirement: A comparison of their similarities and differences. Personnel Psychology, 51, 643-665.

Allen, J. M., \& Hart, M. (1998). Training older workers: Implications for HRD/HPT professionals. Performance Improvement Quarterly, 11, 91-102. 
Allen, T. D., Poteet, M. L., \& Russell, J. E. A. (1998). Attitudes of managers who are more or less career plateaued. The Career Development Quarterly, 47, 159-172.

Au, D. W. H., Crossley, T. F., \& Schellhorn, M. (2005). The effect of health changes and long-term health on the work activity of older Canadians. Health Economics, 14, 999-1018.

Barnes-Farrell, J. L. (2003). Beyond health and wealth: Attitudinal and other influences on retirement decisionmaking. In G. A. Adams, \& T. A. Beehr (Eds.), Retirement: Reasons, processes and results (pp. 159-187). New York: Springer Publishing Company, Inc.

Beehr, T. A., \& Bowling, N. A. (2002). Career issues facing older workers. In D. Feldman (Ed.), Work careers: A developmental perspective (pp. 214-241). San Francisco: Jossey-Bass.

Beehr, T. A., Glazer, S., Nielson, N. L., \& Farmer, S. J. (2000). Work and nonwork predictors of employees' retirement ages. Journal of Vocational Behavior, 57, 206-225.

Blader, S. L., \& Tyler, T. R. (2003). What constitutes fairness in work settings? A four-component model of procedural justice. Human Resource Management Review, 13, 107-126.

Brown, S. P., \& Leigh, T. W. (1996). A new look at psychological climate and its relationship to job involvement, effort, and performance. Journal of Applied Psychology, 81, 358-368.

Byrne, B. M. (1998). Structural equation modeling with LISREL, PRELIS, and SIMPLIS: Basic concepts, applications, and programming. Mahwah, NJ: Lawrence Erlbaum Associates.

Callanan, G. A., \& Greenhaus, J. H. (2008). The baby boom generation and career management: A call to action. Advances in Developing Human Resources, 10, 70-85.

Canadian Labour and Business Centre. (2004). Workforce Profile of the Manufacturing Sector. Retrieved on August 22, 2004 from http://www.clbc.ca/files/Reports

Canadian Nursing Advisory Committee. (2002). The Health of Canadians-the Federal Role. Final Report. Volume Six: Recommendations for Reform. Retrieved on January 28, 2005 from http:www.parl.gc.ca/37/2/ parlbus/commbus/senate/com-e/soci-e/rep-e/repoctvol6part4-e.htm

Chen, Y.-P., \& Scott, J. C. (2003). Gradual retirement: An additional option in work and retirement. North American Actuarial Journal, 7, 62-74.

Cho, A., \& Mor Barak, M. E. (2008). Understanding of diversity and inclusion in a perceived homogeneous culture: A study of organizational commitment and job performance among Korean employees. Administration in Social Work, 32, 100-126.

Choy, M. R., \& Savery, L. K. (1998). Employee plateauing: Some workplace attitudes. Journal of Management Development, 17, 392-401.

Colquitt, J. A. (2001). On the dimensionality of organizational justice: A construct validation of a measure. Journal of Applied Psychology, 86, 386-400.

Committee for Economic Development. (1999). New Opportunities for Older Workers. Retrieved on September 13, 2004 from http://www.ced.org/docs/report/report_older.pdf

Cooper-Hakim, A., \& Viswesvaran, C. (2005). The construct of work commitment: Testing an integrative framework. Psychological Bulletin, 131, 241-259.

Davey, J. (2008). What influences retirement decisions? Social Policy Journal of New Zealand, 33, $110-125$.

Desmette, D., \& Gaillard, M. (2008). When a "worker" becomes an "older worker": The effects of age-related social identity on attitudes towards retirement and work. Career Development International, 13, 168-185.

Dorn, D., \& Sousa-Poza, A. (2007). 'Voluntary' and 'Involuntary' Early Retirement: An International Analysis. IZA Discussion Paper No. 2714. Bonn: Forschungsinstitut zur Zukunft der Arbeit Institute for the Study of Labor.

Dwyer, D. S., \& Mitchell, O. S. (1999). Health problems as determinants of retirement: Are self-rated measures endogenous? Journal of Health Economics, 18, 173-193.

Edgar, R., \& Geare, A. (2005). HRM practice and employee attitudes: Different measures-different results. Personnel Review, 34, 534-549.

Ekerdt, D. J., DeViney, S., \& Kosloski, K. (1996). Profiling plans for retirement. Journal of Gerontology: Social Sciences, 51B, S140-S149.

European Foundation for the Improvement of Living and Working Conditions. (2004). The Workplace of the Future-Managing the Challenge of an Ageing Workforce. Retrieved on June 23, 2004 from http://www.emcc.eurofound.eu.int/content/source/eu04014a.html

Farr, J. L., \& Ringseis, E. L. (2002). The older worker in organizational context: Beyond the individual. In C. L. Cooper, \& I. T. Robertson (Eds.), International review of industrial and organizational psychology (Vol. 17, pp. 31-75). New York: John Wiley \& Sons, Ltd.

Feldman, D. C., \& Turnley, W. H. (1995). Factors influencing intentions to retire: An empirical test of theoretical propositions. Management Research News, 18, 28-35. 
Finlayson, B., Dixon, J., Meadows, S., \& Blair, G. (2002). Mind the gap: The extent of the NHS nursing shortage. British Medical Journal, 325, 538-541.

Frank, F. D., Finnegan, R. P., \& Taylor, C. R. (2004). The race for talent: Retaining and engaging workers in the 21st century. Human Resource Planning, 27, 12-25.

Goldberg, B. (2000). Age works: What corporate America must do to survive the graying of the workforce. New York: The Free Press.

Graham, J. W. (1991). An essay on organizational citizenship behavior. Employee Responsibilities and Rights Journal, 4, 249-270.

Griffiths, A. (1997). Aging, health, and productivity: A challenge for the new millennium. Work \& Stress, 11, 197214.

Guest, D. E. (1999). Human resource management-the workers' verdict. Human Resource Management Journal, 9, 5-25.

Hale, N. (1990). The older worker: Effective strategies for management and human resource development. San Francisco: Jossey-Bass Publishers.

Hanisch, K. A. (1994). Reasons people retire and their relations to attitudinal and behavioral correlates in retirement. Journal of Vocational Behavior, 45, 1-16.

Hatcher, B. J., Bleich, M. R., Connolly, C., Davis, K., O’Neill Hewlett, P., \& Stokely Hill, K. (2006). Wisdom at work: The importance of the older and experienced nurse in the workplace. Princeton, NJ: Robert Wood Johnson Foundation.

Health Resources and Services Administration. (2004). What is behind HRSA's projected supply, demand, and shortage of registered nurses? Washington, DC: U.S. Department of Health and Human Services.

Hedge, J. W., Borman, W. C., \& Lammlein, S. E. (2006). The aging workforce: Realities, myths, and implications for organizations. Washington, DC: American Psychological Association.

Henley, A. B., Shook, C. L., \& Peterson, M. (2006). The presence of equivalent models in strategic management research using structural equation modeling. Organizational Research Methods, 9, 516-535.

Jöreskog, K., \& Sörbom, D. (2003). LISREL ${ }^{\mathbb{R}}$ 8.54. Chicago: Scientific Software International.

Kelloway, E. K. (1998). Using LISREL for structural equation modeling. Thousand Oaks, CA: Sage Publications, Inc.

Kim, H., \& DeVaney, S. A. (2005). The selection of partial or full retirement by older workers. Journal of Family and Economic Issues, 26, 371-394.

Kooij, D., de Lange, A., Jansen, P., \& Dikkers, J. (2007). Older workers' motivation to continue to work: Five meanings of age. A conceptual review. Journal of Managerial Psychology, 23, 364-394.

Kuvaas, B. (2007). An exploration of how the employee-organization relationship affects the linkage between perception of developmental human resource practices and employee outcomes. Journal of Management Studies, 45I, 1-25.

London, M., \& Howat, G. (1978). The relationship between employee commitment and conflict resolution behavior. Journal of Vocational Behavior, 13, 1-14.

Lyons, T. F. (1971). Role clarity, need for clarity, satisfaction, tension, and withdrawal. Organizational Behavior and Human Performance, 6, 99-110.

Macey, W. H., \& Schneider, B. (2008). The meaning of employee engagement. Industrial and Organizational Psychology, 1, 3-30.

Manpower. (2007). The new agenda for an older workforce. Milwaukee, WI: Manpower Inc.

Masterson, S. S., Lewis, K., Goldman, B. M., \& Taylor, M. S. (2000). Integrating justice and social exchange: The differing effects of fair procedures and treatment on work relationships. Academy of Management Journal, 43, $738-748$.

Masterson, S. S., \& Stamper, C. L. (2003). Perceived organizational membership: An aggregate framework representing the employee-organization relationship. Journal of Organizational Behavior, 24, 473-490.

McEvoy, G. M., \& Blahna, M. J. (2001). Engagement or disengagement? Older workers and the looming labor shortage. Business Horizons, 44, 46-52.

McGarry, K. (2004). Health and retirement: Do changes in health affect retirement expectations? The Journal of Human Resources, 39, 624-648.

McMullin, J. A., \& Cooke, M. (2004). Labour Force Ageing and Skill Shortages in Canada and Ontario. Retrieved on August 31, 2004 from the Canadian Policy Research Networks Inc. Website http://www.cprn.org/documents/ 31517_en.pdf

Meier, E. L. (1988). Managing an older workforce. In M. C. Borus, H. S. Parnes, S. H. Sandell, \& B. Seidman (Eds.), The older worker (pp. 167-189). Madison, WI: Industrial Relations Research Association. 
Mein, G., Martikainen, P., Stansfeld, S. A., Brunner, E. J., Fuhrer, R., \& Marmot, M. G. (2000). Predictors of early retirement in British civil servants. Age and Ageing, 29, 529-536.

Mermin, G. B. T., Johnson, R. W., \& Murphy, D. P. (2007). Why do boomers plan to work longer? Journal of Gerontology: Social Sciences, 62B, S286-S294.

Meyer, J. P., \& Smith, C. A. (2000). HRM practices and organizational commitment: Test of a mediation model. Canadian Journal of Administrative Studies, 17, 319-331.

Mitchell, C. (2006). Age and opportunity: Plan strategically to get the most out of a maturing workforce. New York: The Conference Board.

Mor-Barak, M. E. (1995). The meaning of work for older adults seeking employment: The generativity factor. International Journal of Aging and Human Development, 41, 325-345.

Mueller, C. W., Wallace, J. E., \& Price, J. L. (1992). Employee commitment: Resolving some issues. Work and Occupations, 19, 211-236.

Ng, T. W. H., \& Feldman, D. C. (2007). Organizational embeddedness and occupational embeddedness across career stages. Journal of Vocational Behavior, 70, 336-351.

O’Brien-Pallas, L., Alksnis, C., Wang, S., Birch, S., Tomblin Murphy, G., Roy, F. A., et al. (2003). Early retirement among RNs: Estimating the size of the problem in Canada. Longwoods Review, 1, 2-9.

O'Brien-Pallas, L., Duffield, C., \& Alksnis, C. (2004). Who will be there to nurse? Journal of Nursing Administration, 34, 298-302.

Oulton, J. A. (2006). The global nursing shortage: An overview of issues and actions. Policy, Politics, \& Nursing Practice, 7, 34S-39S.

Paré, G., \& Tremblay, M. (2007). The influence of high-involvement human resources practices, procedural justice, organizational commitment, and citizenship behaviors on information technology professionals' turnover intentions. Group \& Organization Management, 32, 326-357.

Parkinson, D. (2002). Voices of experience: Mature workers in the future workforce. NY: The Conference Board, Inc. Report Number R-1319-02-RR.

Patrickson, M. (1998). Reversing the trend toward early retirement. In M. Patrickson, \& L. Hartmann (Eds.), Managing an ageing workforce (pp. 106-118). Warriewood, Australia: Business and Professional Publishing, Woodslane Pty Limited.

Patrickson, M. (2003). Human resource management and the ageing workforce. In R. Wiesner, \& B. Millet (Eds.), Human resource management: Challenges and future directions (pp. 33-43). Milton, Queensland: Wiley.

Peterson, S. J., \& Spiker, B. K. (2005). Establishing the positive contributory value of older workers: A positive psychology perspective. Organizational Dynamics, 34, 153-167.

Pfeffer, J. (1985). Organizational demography: Implications for management. California Management Review, 28, 67-81.

Pitt-Catsouphes, M., \& Matz-Costa, C. (2008). The multi-generational workforce: Workplace flexibility and engagement. Community, Work \& Family, 11, 215-229.

Policy Research Initiative. (2005). Encouraging choice in work and retirement project report. Ottawa: Government of Canada.

Pyper, W. (2006). Aging, health and work. Perspectives on Labour and Income, 7, 5-15.

Quinn, J. F. (1999). Retirement patterns and bridge jobs in the 1990s. EBRI Issue Brief Number 206. Washington, DC: Employee Benefit Research Institute.

Rappaport, A., Bancroft, E., \& Okum, L. (2003). The aging workforce raises new talent management issues for employers. Journal of Organizational Excellence, 23, 55-66.

Remery, C., Jenkens, K., Schippers, U., \& Ekamper, P. (2003). Managing an aging workforce and a tight labor market: Views held by Dutch employers. Population Research and Policy Review, 22, 21-40.

Rix, S. E. (2004). Aging and Work-A View from the United States. Retrieved on June 17, 2004 from http:// research.aarp.org/econ/2004_02_work.pdf

Rousseau, D. M. (1995). Psychological contracts in organizations: Understanding written and unwritten agreements. Thousand Oaks, CA: Sage.

Rousseau, D. M., \& Greller, M. M. (1994). Human resources practices: Administrative contract makers. Human Resource Management, 33, 385-401.

Saks, A. M. (2006). Antecedents and consequences of employee engagement. Journal of Managerial Psychology, 21, 600-619.

Schmidt, J. A., \& Lee, K. (2008). Voluntary retirement and organizational turnover intentions: The differential associations with work and non-work commitment constructs. Journal of Business Psychology, 22, $297-309$.

Shacklock, K., \& Brunetto, Y. (2005). Employees' perceptions of the factors affecting their decisions to retire. International Journal of Organisational Behaviour, 10, 740-756. 
Shacklock, K., Fulop, L., \& Hort, L. (2007). Managing older worker exit and re-entry practices: A "revolving door"? Asia Pacific Journal of Human Resources, 45, 151-167.

Simoens, S., Villeneuve, M., \& Hurst, J. (2005). Tackling Nurse Shortages in OECD Countries. OECD Health Working Papers, No. 19. Paris: Organisation for Economic Co-operation and Development.

Stamper, C. L., \& Masterson, S. S. (2002). Insider or outsider? How employee perceptions of insider status affect their work behavior. Journal of Organizational Behavior, 23, 875-894.

Statistics Canada. (2004). The Canadian Labour Market at a Glance 2003. Ottawa: Statistics Canada.

Statistics Canada. (2007a). Age Groups and Sex for the Population of Canada, Provinces and Territories, 1921 to 2006 Censuses. Ottawa: Statistics Canada.

Statistics Canada. (2007b). Portrait of the Canadian Population in 2006, by Age and Sex: National Portrait. Ottawa: Statistics Canada.

Taylor, M. A., \& Shore, L. M. (1995). Predictors of planned retirement age: An application of Beehr's model. Psychology and Aging, 10, 76-83.

Taylor, P., \& Walker, A. (1998a). Employers and older workers: Attitudes and employment practices. Aging and Society, 18, 641-658.

Taylor, P., \& Walker, A. (1998b). Policies and practices towards older workers: A framework for comparative research. Human Resource Management Journal, 8, 61-76.

The Conference Board of Canada. (2006). Canada's demographic revolution: Adjusting to an aging population. Ottawa: Author.

Turcotte, M., \& Schellenberg, G. (2005). Job strain and retirement. Perspectives on Labour and Income, 6, $13-17$.

United Nations. (2007). World Economic and Social Survey 2007: Development in an ageing world. New York: United Nations.

Vandenberg, R. J., \& Lance, C. E. (2001). A review and synthesis of the measurement invariance literature: Suggestions, practices, and recommendations for organizational research. Organizational Research Methods, 3 , 4-70.

West, J. P., \& Berman, E. M. (1996). A national survey: Managerial responses to an aging municipal workforce. Review of Public Personnel Administration, 16, 38-58. 